\title{
Caracterização Morfofisiológica de Genótipos de Cornichão (Lotus corniculatus L.) ${ }^{1}$ \\ Maria Tereza Bolzon Soster ${ }^{2}$, Simone Meredith Scheffer-Basso ${ }^{3}$, Miguel Dall'Agnol ${ }^{4}$
}

\begin{abstract}
RESUMO - O cornichão cv. São Gabriel é uma importante leguminosa hiberno-primaveril para o sul do Brasil, cuja principal limitação é a baixa persistência sob pastejo. Objetivou-se, com este trabalho, avaliar oito populações desse cultivar, selecionadas sob pastejo ou corte, comparando um genótipo rizomatoso (cv. ARS-2620) com um cultivar uruguaio sem rizomas (cv. Trueno), com a finalidade de verificar a variabilidade morfológica e caracteres vinculados à tolerância ao pastejo. Foram conduzidos dois ensaios em casa-de-vegetação, com plantas cultivadas em vasos, até alcançarem o florescimento pleno. Foi observada variabilidade morfofisiológica no germoplasma, como morfologia das folhas, dos caules e das coroas, assim como hábito de crescimento. Somente no cv. ARS-2620 foram observados rizomas típicos, mas todos os genótipos apresentaram hastes subterrâneas. O cv. ARS-2620 foi susceptível a ácaros, observando-se sintomas de antracnose (Colletotrichum sp.) em duas populações. A variabilidade morfofisiológica das populações do cv. São Gabriel poderá ser explorada em programas de melhoramento do cornichão.
\end{abstract}

Palavras-chave: hábito de crescimento, morfologia, rizomas

\section{Morphophysiological Characterization on the Birdsfoot Trefoil Genotypes (Lotus corniculatus L.)}

\begin{abstract}
The birdsfoot trefoil cv. São Gabriel is an important winter-spring growing legume in the Southern Brazil, which main limitation is the low persistence under grazing. The objective of this work was to evaluate eight populations of this cultivar, selected under grazing or cut, comparing with one rhizomatous genotype (cv. ARS-2620) and a cultivar from Uruguay without rhizomes (cv. Trueno), with the purpose to evaluate the morphological variability and characters linked to grazing tolerance. Two assays were conducted in the greenhouse with plants grown in pots until the full flowering stage. It was observed morphological variability in the germplasm, with variation in the leaf, stem and crown morphology as well as in growth habit. Only in the cv. ARS-2620 was observed typical rhizomes, but all the genotypes showed subterraneous stems. The cv. ARS-2620 was susceptible to mites and two populations showed symptoms of anthracnose (Colletotrichum sp.). The morphophysiological variability of the cv. São Gabriel populations can be used in a birdsfoot trefoil breeding programs.
\end{abstract}

Key Words: growth habit, morphology, rhizomes

\section{Introdução}

O cornichão (Lotus corniculatus L.) é uma leguminosa forrageira perene hiberno-primaveril, de origem européia e mediterrânea, porém distribuída em todas as partes do mundo, com exceção de regiões muito frias e de áreas muito tropicais (Beuselinck, 1999). Morfologicamente, apresenta variações quanto ao tamanho, à forma e pubescência, à coloração das folhas, entre outras. O hábito de crescimento, geralmente, é ereto, embora possa ser prostrado ou ascendente (Seaney \& Henson, 1970). A grande variabilidade dos genótipos dessa espécie deve-se à ampla base genética e à sua forma tetraplóide, embora também seja encontrado na forma diplóide - a exemplo de alguns genótipos rizomatosos originários do Marrocos (Steiner \& Garcia de Los Santos, 2001) -, como também a hibridações interespecíficas (Grant, 1999).

A partir da descoberta de tipos rizomatosos de cornichão, em 1988, muitos trabalhos se voltaram para a incorporação dessa característica em cultivares comerciais, como os cvs. ARS-2620 e ARS-2622 (Kallenbach et al., 2003). Acredita-se que o hábito de crescimento rizomatoso pode contribuir para o aumento da persistência da espécie, visto que os rizomas funcionam como reservas e como órgãos de propagação vegetativa ( $\mathrm{Li} \&$ Beuselinck, 1996).

\footnotetext{
1 Parte da dissertação de mestrado da primeira autora, financiada pela Fundação de Amparo à Pesquisa do Estado do Rio Grande do Sul (Fapergs).

2 Eng. Agr., E.mail: tsoster@zipmail.com.br

3 Eng. Agr., Dra., Professora da Universidade de Passo Fundo. E.mail: simone@upf.br

4 Eng. Agr., PhD., Professor da Universidade Federal do Rio Grande do Sul, Bolsista CNPq.
} 
Poucos trabalhos têm sido conduzidos com estes genótipos, quanto à resposta a corte ou pastejo (Kallenbach et al., 2001). Na literatura nacional, não havia, até o desenvolvimento deste trabalho, quaisquer informações sobre a adaptação e a produção de forragem dos tipos rizomatosos.

No Brasil, o único cultivar disponível é o São Gabriel, desenvolvido pela Estação Experimental de São Gabriel, RS, a partir de pesquisas entre 1955 e 1965, tendo seu cultivo se expandido para outros países da América do Sul (Paim, 1988). Desde então, nenhum outro cultivar foi desenvolvido no país. Esse cultivar é caracterizado pelo rápido crescimento inicial, boa produtividade e elevada qualidade de forragem, longo período vegetativo e boa ressemeadura natural. Contudo, apresenta problemas de persistência, principalmente por causa de seu hábito de crescimento ereto (Oliveira \& Paim, 1990). A persistência tem sido prioridade nos programas de melhoramento de leguminosas em diversos países. No entanto, segundo Caradus \& Williams (1989), muitos fatores estão associados com tal atributo, tornando-o um problema geneticamente complexo.

O presente trabalho foi conduzido com o objetivo de caracterizar morfofisiologicamente oito populações de cornichão cv. São Gabriel, com a finalidade de identificar caracteres vinculados à persistência que possam subsidiar futuros trabalhos de melhoramento, comparando-as com um cultivar rizomatoso e um cultivar uruguaio.

\section{Material e Métodos}

O trabalho foi conduzido em casa-de-vegetação, na Universidade de Passo Fundo, entre maio/2001 e abril/2002. O município de Passo Fundo está localizado a $28^{\circ} 15^{\prime} \mathrm{S}$ e $52^{\circ} 24^{\prime \prime} \mathrm{W}$ e a $687 \mathrm{~m}$ de altitude, na região do Planalto Médio do Rio Grande do Sul. A variabilidade morfológica e a identificação de caracteres vinculados à persistência foram verificadas em dez tratamentos, que consistiram de dez genótipos: oito populações selecionadas do cv. São Gabriel, denominadas P3, P4, P9, P11, P37, P38, Corte e Alqueire, o cv. Trueno (Uruguai) e o cv. ARS-2620 (Estados Unidos), sendo esse último um resultado de cruzamentos do cornichão comum, sem rizomas, com um genótipo rizomatoso proveniente do Marrocos e caracterizado pela presença de rizomas e hábito de crescimento semi-decumbente. A metodologia completa sobre o processo de seleção das populações acima referidas consta em Perez (2003). Resumidamente, as populações P3, P4, P9, P11, P37 e P38 foram oriundas de um bloco de policruzamento estabelecido com o plantio de clones de plantas do cv. São Gabriel existentes em uma área pastejada há diversos anos, em São Gabriel, RS. A população Corte é uma progênie originada a partir de plantas sobreviventes a um manejo de cortes semanais rentes ao solo, durante nove meses, na Estação Experimental Agronômica da Universidade Federal do Rio Grande do Sul, em Eldorado do Sul, RS. A população Alqueire foi obtida a partir de plantas do cv. São Gabriel sobreviventes ao pastejo, após seis anos da implantação em campo nativo, em Rio Pardo, RS, que, posteriormente, foram submetidas, durante a primavera-verão, a um regime de pastejo moderado e, no verão seguinte, a um regime de pastejo intenso e contínuo.

Para o estabelecimento dos ensaios, foram obtidas as plântulas a partir da germinação de sementes em bandejas de isopor, em ambiente protegido. Seis semanas após a germinação, as plantas foram transplantadas para vasos contendo $5 \mathrm{~kg}$ de solo corrigido e adubado, sendo mantida uma planta por vaso. As plantas foram irrigadas regularmente e receberam aplicação de fungicidas e acaricidas, na tentativa de controlar oídio (Eryisiphe sp.), antracnose (Colletotrichum sp.) e ácaros.

Foram organizados dois ensaios, de acordo com o objetivo do trabalho - caracterizar o sistema aéreo e o sistema subterrâneo e coroa:

Ensaio I - Caracterização do sistema aéreo. Adotou-se o delineamento de blocos ao acaso, com seis repetições. As plantas foram cultivadas até o florescimento pleno, quando, então, foram avaliadas quanto: a) fenologia: o comportamento fenológico foi descrito pelo número de dias decorrido entre a semeadura e o florescimento pleno, ou seja, quando mais de $50 \%$ das hastes apresentavam flores; além disso, foi calculado o percentual de plantas florescidas dentro de cada genótipo, pela contagem de plantas florescidas nos diversos blocos; b) comprimento de entrenós e de pedúnculos florais; c) número de flores/ umbela; d) tamanho das folhas: foi tomada a largura das folhas, pela medida da dimensão transversal entre os dois folíolos laterais; no sentido vertical, foi medido o comprimento do folíolo central, desde sua inserção no pecíolo; e) aparência das folhas: foram observados caracteres como cor, pubescência e forma dos folíolos; f) hábito de crescimento das plantas: as plantas foram classificadas de acordo com Steiner 
\& Garcia de los Santos (2001) em: ereto, ascendente e decumbente;

Ensaio II - Caracterização do sistema subterrâneo. Foi adotado delineamento de blocos ao acaso, com quatro repetições. As plantas foram colhidas no estádio de florescimento pleno. A coroa, definida como a porção basilar lignificada do caule na região do nó cotiledonar, foi avaliada quanto ao diâmetro. A parte subterrânea foi lavada, para eliminação da terra, e, posteriormente, foram verificados os tipos de caules presentes: rizomas e/ou hastes subterrâneas. As hastes aéreas foram classificadas quanto à consistência (ocas/sólidas) e à capacidade de enraizamento. Quanto aos aspectos fitossanitários, as moléstias e pragas observadas foram identificadas, avaliando-se a suscetibilidade dos genótipos às mesmas.

Como houve variabilidade intragenotípica quanto à fenologia, os resultados foram submetidos à análise da variância pelo método matricial e as médias foram comparadas pelo teste Tukey $(5 \%)$.

\section{Resultados e Discussão}

Quanto ao intervalo médio da semeadura ao florescimento pleno, não foi observada diferença significativa entre os genótipos (Tabela 1), observando-se variação entre 173 e 239 dias, em amplitude média de 53 dias. No entanto, a variabilidade intragenotípica para este atributo variou entre 2 (cv. Trueno) e 96 dias (população Corte), evidenciando maior ou menor sincronia de florescimento. O tempo decorrido até o florescimento pleno, evidenciado neste trabalho, está de acordo com as observações de Oliveira et al. (1990), que verificaram o início do florescimento no cv. São Gabriel, aos 150 dias após a semeadura, sendo considerado um comportamento tardio.

Além da variabilidade quanto ao tempo decorrido até o florescimento pleno, foi constatada variabilidade para o percentual de plantas florescidas. Verificou-se que apenas quatro genótipos tiveram as plantas florescidas em todos os blocos, referentes às populações do cv. São Gabriel. O cv. ARS-2620 teve apenas um terço das plantas florescidas nas condições ambientais do ensaio. Em ensaio no campo, Soster (2003) observou que, do total de 30 plantas, todas entraram em florescimento pleno e na mesma época dos demais genótipos de cornichão estudados, incluindo as populações testadas no presente estudo.

Quanto ao hábito de crescimento, após observação das plantas ao longo do tempo, verificou-se que seria mais adequado descrever sua forma de crescimento a partir do hábito apresentado pelas hastes laterais e centrais, segundo Steiner \& Garcia de Los Santos (2001), porém com algumas modificações. Verificou-se que somente o cv. ARS-2620 apresentou o mesmo hábito de crescimento nos dois tipos de hastes: centrais e laterais (Tabela 2). As plantas que apresentaram hastes mais eretas foram aquelas com

Tabela 1 - Aspectos fenológicos de genótipos de Lotus corniculatus L.

Table 1 - Phenological features of Lotus corniculatus L. genotypes

\begin{tabular}{|c|c|c|c|}
\hline $\begin{array}{l}\text { Genótipos } \\
\text { Genotypes }\end{array}$ & $\begin{array}{l}\text { Intervalo semeadura-florescimento } \\
\text { pleno (dias) } \\
\text { Sowing-full flowering interval (days) }\end{array}$ & $\begin{array}{l}\text { Amplitude do período de } \\
\text { florescimento (dias) } \\
\text { Flowering period range (days) }\end{array}$ & $\begin{array}{l}\text { Plantas florescidas } \\
\text { Flowered plants (\%) }\end{array}$ \\
\hline ARS-2620 & $239 \mathrm{~ns}$ & $231-247$ & 33 \\
\hline Alqueire & 203 & $178-214$ & 66 \\
\hline P11 & 200 & $170-262$ & 100 \\
\hline P9 & 198 & $174-239$ & 100 \\
\hline Corte & 197 & $171-270$ & 66 \\
\hline P3 & 197 & $169-235$ & 100 \\
\hline P37 & 196 & $173-262$ & 83 \\
\hline P4 & 193 & $170-256$ & 66 \\
\hline P38 & 174 & $170-182$ & 100 \\
\hline Trueno & 173 & $172-174$ & 50 \\
\hline Médias & 197 & $184-237$ & 72 \\
\hline \multicolumn{4}{|l|}{ Means } \\
\hline $\mathrm{CV}(\%)$ & 14,0 & & \\
\hline
\end{tabular}

$\mathrm{ns}=$ diferença não-significativa pelo teste $\mathrm{F}$.

$n s=$ not significant difference by $F$ test.

R. Bras. Zootec., v.33, n.6, p.1654-1661, 2004 (Supl. 1) 
as maiores estaturas, ao passo que o cv. ARS-2620 apresentou a menor estatura, compatível com seu hábito de crescimento prostrado.

Entre as populações do cv. São Gabriel, P37, P38, Alqueire e Corte mostraram hábito de crescimento mais prostrado que as demais, o que pode ser vantajoso sob pastejo, pois plantas mais prostradas apresentam suas gemas de crescimento próximas à superfície do solo e, portanto, estão mais protegidas da ação dos herbívoros (Nelson \& Moser, 1994). A importância do hábito de crescimento para o cornichão foi confirmada no trabalho de Caroso et al. (1981), por meio de avaliações sob cortes, no qual progênies e cultivares mais eretos foram menos persistentes.

Para caracteres morfológicos relacionados às hastes e às flores, observou-se variabilidade apenas quanto ao número de flores/umbela (Tabela 3).

O genótipo rizomatoso (cv. ARS-2620) mostrou poucas flores/umbela, concordando com resultados de Beuselinck et al. (1996), para acessos de cornichão rizomatosos oriundos do Marrocos. Maior número de flores/umbela pode significar maior produção de legumes e, conseqüentemente, de sementes, garantindo melhor ressemeadura da espécie em nível de campo. Para comprimento de entrenó, não houve diferença significativa entre os genótipos, apesar da considerável amplitude observada. Notou-se, porém, que o genótipo rizomatoso se caracterizou por apresentar entrenós mais curtos, o que condiz com sua forma de crescimento mais compacta.

Para as características das folhas, observou-se variabilidade para tamanho e forma dos folíolos, pubescência e coloração (Tabela 4).

Apenas os genótipos P9, Alqueire, Corte e o cv. ARS-2620 foram glabros; os demais apresentaram pubescência, em algum grau. A coloração predominante dos genótipos foi verde-escura, exceto no cv. ARS-2620, que apresentou coloração verde menos intensa. As folhas mais largas foram observadas na população P3, ao passo que as menores, na população P4. Steiner \& Garcia de los Santos (2001) também observaram variabilidade quanto à pubescência, tamanho e forma de folíolos em cornichão. Beuselinck et al. (1996) descreveram alto grau de variabilidade em Lotus para tamanho de folhas, número de flores e comprimento de pedúnculo.

A coroa é uma importante região para o desenvolvimento de novas hastes após o pastejo e, portanto, para sua longevidade. Em cornichão, segundo Marquez-Ortiz et al. (1996), alta produtividade e persistência podem estar associadas à morfologia da coroa, indicando maior ou menor vulnerabilidade a

Tabela 2 - Estatura e hábito de crescimento de genótipos de Lotus corniculatus L.

Table 2 - Height and growth habit of Lotus corniculatus L. genotypes

\begin{tabular}{lccc}
\hline $\begin{array}{l}\text { Genótipos } \\
\text { Genotypes }\end{array}$ & $\begin{array}{c}\text { Estatura }(\mathrm{cm}) \\
\text { Height }\end{array}$ & \multicolumn{2}{c}{$\begin{array}{c}\text { Hábito de crescimento } \\
\text { Growth habit }\end{array}$} \\
\hline P9 & & $\begin{array}{c}\text { Hastes laterais } \\
\text { Lateral } \\
\text { stems }\end{array}$ \\
Trueno & $30,2 \mathrm{a}$ & Ereto & Decumbente \\
C11 & $21,3 \mathrm{ab}$ & Ascendente & Decumbente \\
P38 & $21,0 \mathrm{ab}$ & Ereto & Decumbente \\
P4 & $18,8 \mathrm{ab}$ & Ascendente & Decumbente \\
P3 & $18,3 \mathrm{ab}$ & Ereto & Decumbente \\
P37 & $14,3 \mathrm{ab}$ & Ereto & Decumbente \\
Alqueire & $14,3 \mathrm{ab}$ & Ascendente & Decumbente \\
Corte & $11,8 \mathrm{~b}$ & Ascendente & Decumbente \\
ARS-2620 & $10,8 \mathrm{~b}$ & Ascendente & Decumbente \\
Médias & $7,5 \mathrm{~b}$ & Ascendente & Ascendente \\
Means & 17,6 & & \\
CV $(\%)$ & 38,4 & & \\
\hline
\end{tabular}

Médias seguidas de letras iguais, na coluna, não diferem pelo teste Tukey a $5 \%$.

Means followed by the same letters, in column, are not different by Tukey test at $5 \%$.

Ereto (Erect).

Ascendente (Ascendent).

Decumbente (Decumbent).

R. Bras. Zootec., v.33, n.6, p.1654-1661, 2004 (Supl. 1) 
Tabela 3 - Comprimento de entrenós e pedúnculos florais e número de flores/umbela de genótipos de Lotus corniculatus L. Table 3 - Internodes length and flowers peduncle and number of flowers/umbel of Lotus corniculatus L. genotypes

\begin{tabular}{lccc}
\hline $\begin{array}{l}\text { Genótipos } \\
\text { Genotypes }\end{array}$ & $\begin{array}{c}\text { Entrenós }(\mathrm{cm}) \\
\text { Internodes }\end{array}$ & $\begin{array}{c}\text { Pedúnculo floral (cm) } \\
\text { Flower peduncle }\end{array}$ & $\begin{array}{c}\mathrm{N}^{\circ} \text { de flores/umbela } \\
\text { N. flowers/umbel }\end{array}$ \\
\hline Trueno & $3,22 \mathrm{~ns}$ & $6,00 \mathrm{~ns}$ & $3,67 \mathrm{~b}$ \\
P4 & 2,65 & 4,38 & $4,67 \mathrm{ab}$ \\
P3 & 2,46 & 3,18 & $4,17 \mathrm{ab}$ \\
P11 & 2,43 & 5,93 & $5,33 \mathrm{ab}$ \\
P37 & 2,42 & 5,27 & $3,73 \mathrm{~b}$ \\
P9 & 2,35 & 3,95 & $5,00 \mathrm{ab}$ \\
Alqueire & 2,27 & 3,40 & $5,83 \mathrm{a}$ \\
Corte & 2,22 & 3,78 & $4,17 \mathrm{ab}$ \\
P38 & 2,13 & 5,11 & $4,67 \mathrm{ab}$ \\
ARS-2620 & 1,71 & 4,92 & $3,67 \mathrm{~b}$ \\
Médias & 2,38 & 4,59 & 4,51 \\
Means & & & 20,06 \\
CV $(\%)$ & 36,71 & 50,8 & \\
\hline
\end{tabular}

Médias seguidas de letras iguais, na coluna, não diferem pelo teste Tukey a $5 \%$.

Means followed by the same letters, in column, are not different by Tukey test at $5 \%$.

ns = diferença não-significativa pelo teste $\mathrm{F}$.

$n s=$ not significant difference by $F$ test.

Tabela 4 - Características de folhas de genótipos de Lotus corniculatus L.

Table 4 - Leaves characteristics of Lotus corniculatus L. genotypes

\begin{tabular}{|c|c|c|c|c|c|}
\hline $\begin{array}{l}\text { Genótipos } \\
\text { Genotypes }\end{array}$ & $\begin{array}{c}\text { Comprimento }(\mathrm{cm}) \\
\text { Lenght }\end{array}$ & $\begin{array}{c}\operatorname{Largura}(\mathrm{cm}) \\
\text { Width }\end{array}$ & $\begin{array}{c}\text { Forma do folíolo } \\
\text { Leaflet shape }\end{array}$ & $\begin{array}{c}\text { Pubescência } \\
\text { Pubescence }\end{array}$ & $\begin{array}{c}\text { Coloração } \\
\text { Color }\end{array}$ \\
\hline P38 & $2,0 \mathrm{a}$ & $1,9 \mathrm{ab}$ & Obovado largo & Presente & Verde escuro \\
\hline Trueno & $1,9 \mathrm{ab}$ & $1,9 \mathrm{ab}$ & Obovado estreito & Presente & Verde escuro \\
\hline Alqueire & $1,9 \mathrm{ab}$ & $1,8 \mathrm{ab}$ & Lanceolado & Ausente & Verde escuro \\
\hline P11 & $1,9 \mathrm{ab}$ & $1,6 \mathrm{ab}$ & Obovado estreito & Presente & Verde escuro \\
\hline P4 & $1,6 \mathrm{abc}$ & $1,4 \mathrm{~b}$ & Obovado estreito & Presente & Verde escuro \\
\hline P9 & $1,6 \mathrm{abc}$ & $1,6 \mathrm{ab}$ & Obovado estreito & Ausente & Verde escuro \\
\hline P37 & $1,6 \mathrm{abc}$ & $1,8 \mathrm{ab}$ & Obovado largo & Presente & Verde escuro \\
\hline Corte & $1,6 \mathrm{abc}$ & $1,7 \mathrm{ab}$ & Obovado largo & Ausente & Verde escuro \\
\hline ARS-2620 & $1,4 \mathrm{abc}$ & $1,6 \mathrm{ab}$ & Obovado largo & Ausente & Verde \\
\hline P3 & $1,3 \mathrm{bc}$ & $2,2 \mathrm{a}$ & Obovado estreito & Presente & Verde escuro \\
\hline Médias & 1,64 & 1,74 & & & \\
\hline \multicolumn{6}{|l|}{ Means } \\
\hline $\mathrm{CV}(\%)$ & 18,0 & 21,1 & & & \\
\hline
\end{tabular}

Médias seguidas de letras iguais, na coluna, não diferem pelo teste Tukey a $5 \%$.

Means followed by the same letters, in column, are not different by Tukey test at $5 \%$.

Obovado largo (Wide obovate); Obovado estreito (Narrow obovate); Lanceolado (Lanceolate); Presente (Present); Ausente (Absent); Verde escuro (Dark green); Verde (Green).

injúrias. Caradus \& Williams (1989) destacam que o cornichão, assim como a alfafa (Medicago sativa L.) e o trevo-vermelho (Trifolium pratense L.), depende da coroa para persistir. Neste estudo, os genótipos de cornichão diferiram entre si quanto ao diâmetro da coroa, destacando-se a população P37, com valor comparável ao cv. ARS-2620 e significativamente superior aos demais, indicando que, dentro do cv. São
Gabriel, há variabilidade para esse importante atributo vinculado ao pastejo.

Quanto à consistência das hastes aéreas, normalmente, o cornichão é descrito como tendo hastes sólidas, ao contrário de uma espécie afim, o Lotus pedunculatus Schkuhr., que possui hastes ocas. No entanto, observou-se que três populações do cv. São Gabriel também mostraram hastes ocas (Tabela 5). 
Beuselinck et al. (1996), em seu trabalho sobre a descrição de acessos de cornichão oriundos do Marrocos, observaram somente hastes sólidas, tal como se descreve para a espécie. No entanto, mais tarde, Steiner \& Garcia de los Santos (2001) observaram hastes ocas em alguns acessos de cornichão provenientes da Espanha, Polônia e Rússia.

Observou-se que todos os genótipos apresentaram hastes subterrâneas, que, apesar de não serem rizomas, são igualmente importantes para a persistência da planta, não como órgão armazenador de reservas, como os rizomas, mas como um local protegido, capaz de dar origem a novas hastes e, por

Tabela 5 - Diâmetro da coroa de genótipos de Lotus corniculatus L.

Table 5 - Crown diameter of Lotus corniculatus L. genotypes

\begin{tabular}{lc}
\hline $\begin{array}{l}\text { Genótipos } \\
\text { Genotypes }\end{array}$ & $\begin{array}{c}\text { Diâmetro }(\mathrm{cm}) \\
\text { Diameter }\end{array}$ \\
\hline P37 & $7,93 \mathrm{a}$ \\
ARS-2620 & $7,40 \mathrm{ab}$ \\
P3 & $7,05 \mathrm{bc}$ \\
P9 & $7,05 \mathrm{bc}$ \\
P11 & $6,90 \mathrm{bcd}$ \\
Alqueire & $6,80 \mathrm{bcd}$ \\
Corte & $6,67 \mathrm{bcd}$ \\
Trueno & $6,55 \mathrm{~cd}$ \\
P4 & $6,25 \mathrm{~d}$ \\
P38 & $6,22 \mathrm{~d}$ \\
Médias & 6,88 \\
Means & \\
CV $(\%)$ & 3,22 \\
\hline
\end{tabular}

Médias seguidas de letras iguais, na coluna, não diferem pelo teste Tukey a $5 \%$.

Means followed by the same letters, in column, are not different by Tukey test at $5 \%$. fragmentação, a novos indivíduos. Essas hastes, por permanecerem abaixo da superfície do solo, mostraram-se aclorofiladas e deram origem a hastes aéreas, que diferiram dos rizomas, por serem mais delgadas e não possuírem folhas escamosas, razão pela qual não foram consideradas rizomas típicos.

Os rizomas descritos no cornichão caracterizam-se por serem subterrâneos, de orientação plagiotrópica, aclorofilados, com folhas escamosas, fotossinteticamente inativas, e raízes adventícias oriundas dos nós ( $\mathrm{Li} \&$ Beuselinck, 1996). Nos acessos rizomatosos encontrados no Marrocos, esses autores observaram que tais caules se desenvolveram a partir de gemas axilares das hastes. Nualsri \& Beuselinck (1998) referem-se à habilidade de algumas plantas de cornichão desenvolverem rizomas em condições de campo, ao passo que em casa-de-vegetação tal característica pode não se expressar, sugerindo grande influência do ambiente. A característica de enraizamento das hastes observada em alguns genótipos (Tabela 6) é bem conhecida em L. pedunculatus (Oliveira \& Paim, 1990) e desejável também para o cornichão, por aumentar a persistência das plantas, pela maior fixação das plantas no solo.

Um dos fatores limitantes ao desempenho e à persistência do cornichão são os problemas causados por fungos que atacam raízes e coroa (Rubio \& Altier, 1995). Neste trabalho, foram observadas plantas atacadas por moléstias e pragas, como oídio (Erysiphe sp.), antracnose (Colletotrichum sp.), podridão (Botrytis sp.) e ácaros (Tabela 7). Segundo Beuselinck et al. (1984), esses patógenos podem causar perdas de até $90 \%$ nos estandes, em menos de três anos. No Uruguai, conforme Stewart \& Altier (1993), a antracnose tem causado problemas na

Tabela 6 - Características do sistema caulinar de genótipos de Lotus corniculatus L. Table 6 - Characteristics of stem system of genotypes of Lotus corniculatus L.

\begin{tabular}{lclc}
\hline $\begin{array}{l}\text { Genótipos } \\
\text { Genotypes }\end{array}$ & $\begin{array}{c}\text { Consistência das hastes } \\
\text { Stem consistence }\end{array}$ & $\begin{array}{c}\text { Rizomas } \\
\text { Rhizomes }\end{array}$ & $\begin{array}{c}\text { Hastes subterrâneas } \\
\text { Underground stems }\end{array}$ \\
\hline P3 & Oco & Ausente & Presente \\
P4 & Oco & Ausente & Presente \\
P9 & Oco & Ausente & Presente \\
P11 & Sólido & Ausente & Presente \\
P37 & Sólido & Ausente & Presente \\
P38 & Sólido & Ausente & Presente \\
Alqueire & Sólido & Ausente & Presente \\
Corte & Sólido & Ausente & Presente \\
ARS-2620 & Oco & Presente & Presente \\
Trueno & Oco & Ausente & Presente
\end{tabular}

Oco (Hollow); Sólido (Solid); Presente (Present); Ausente (Absent).

R. Bras. Zootec., v.33, n.6, p.1654-1661, 2004 (Supl. 1) 
Tabela 7 - Ocorrência de moléstidas e ácaros em genótipos de Lotus corniculatus L.

Table 7 - Ocorrence of disease and mites in Lotus corniculatus L. genotypes

\begin{tabular}{lcccc}
\hline $\begin{array}{l}\text { Genótipos } \\
\text { Genotypes }\end{array}$ & \multicolumn{3}{c}{$\begin{array}{c}\text { Moléstias } \\
\text { Diseases }\end{array}$} & $\begin{array}{c}\text { Ácaros } \\
\text { Mites }\end{array}$ \\
\cline { 2 - 5 } & Oídio (Erysiphe sp.) & Antracnose (Colletotrichum sp.) & Botrytis sp. \\
\hline P3 & + & - & - & - \\
P4 & + & + & + & - \\
P9 & + & - & - & - \\
P11 & + & - & - & - \\
P37 & + & + & - & - \\
P38 & + & - & + & - \\
Alqueire & + & - & - & - \\
Corte & + & - & - & - \\
ARS-2620 & + & - & - & - \\
Trueno & + & - & - & - \\
\hline
\end{tabular}

Ocorrência de moléstias ou ácaros em menor (+) ou maior (++) grau; (-) ausência de moléstia ou ácaros.

Disease or mite occurrence in smaller (+) or higher degree (++); (-) absence of diseases or mites.

produção de sementes de cornichão, sugerindo maior atenção para essa doença. O fungo Botrytis é causador de podridões e sobrevive no inverno, atacando em temperaturas amenas (em torno de $15^{\circ} \mathrm{C}$ ), podendo danificar coroas e outras partes da planta em muitas espécies (The Plant..., 2003).

Provavelmente, a incidência de Botrytis sp. observada neste trabalho esteja vinculada às condições do local do ensaio, pois, em ambientes fechados, como casas-de-vegetação sem controle climático, a umidade geralmente é elevada. Apesar de todos os genótipos terem sido atacados por oídio, a população Alqueire foi a que demonstrou maior sensibilidade, perdendo grande parte das folhas. Após o ataque de oídio, foi observado o encurtamento dos entrenós de todos os genótipos. Quanto aos ácaros, o cv. ARS2620 foi o único genótipo suscetível, não havendo, ainda, relato na literatura sobre tal comportamento nesse material.

É importante destacar que, apesar de as plantas não terem sido testadas para tais doenças, uma vez que não era o objetivo do ensaio, para os trabalhos de melhoramento genético dessa espécie, esta variabilidade deve ser considerada, uma vez que todos os genótipos foram expostos às mesmas condições ambientais e fontes de inóculo.

\section{Conclusões}

Há variabilidade nos genótipos de cornichão quanto à morfologia e susceptibilidade a doenças e ácaros, destacando-se a variabilidade quanto ao hábito de crescimento e diâmetro da coroa, que poderá ser explorada em um programa de melhoramento da espécie.

\section{Literatura Citada}

BEUSELINCK, P.R. Trefoil: The science and technology of Lotus. 28.ed. Madison: CSSA, 1999. p.9.

BEUSELINCK, P.R.; LI, B.; STEINER, J.J. Rhizomatous Lotus corniculatus L.: I. Taxonomic and cytological study. Crop Science, v.36, n.2, p.179-185, 1996.

BEUSELINCK, P.R.; PETERS, E.J.; McGRAW, R.L. Cultivar and management effects on stand persistence of birdsfoot trefoil. Agronomy Journal, v.76, n.2, p.490-492, 1984.

CARADUS, J.R.; WILLIAMS, W.M. Breeding for legume persistence in New Zealand. In: MARTEN, G.C.; MATCHES, A.G.; BARNES, R.F. et al. (Eds.). Persistence of forage legumes. 2.ed. Madison: ASA, 1989. p.523-540.

CAROSO, G.F.; PAIM, N.R.; PRATES, E.R. Avaliação da produção e persistência de progênies e cultivares de Lotus corniculatus L. Pesquisa Agropecuária Brasileira, v.16, n.3, p.341-346, 1981.

GRANT, W. Interspecific hybridization and amphidiploid of Lotus as it relates to phylogeny and evolution. In: BEUSELINCK, P.R. (Ed.). Trefoil: the science and technology of Lotus. 28.ed. Madison: CSSA, 1999. p.1-20.

KALLENBACH, R.L.; McGRAW, R.L.; BEUSELINCK, P.R. et al. Summer and autumn growth of rhizomatous birdsfoot trefoil. Crop Science, v.41, p.149-156, 2001.

KALLENBACH, R.L.; ROBERTS, C.; BEUSELINCK, P.R. et al. Performance of beef cattle on mixtures and monoculture of rhizomatous birdsfoot trefoil and tall fescue. Disponível em: <http://www.nps.ars.usda.gov/ projects/projects. Acessado em 08 de janeiro de 2003.

LI, B.; BEUSELINCK, P.R. Rhizomatous Lotus corniculatus L.: II. Morphology and anatomy of rhizomes. Crop Science, v.36 n.2, p.407-411, 1996. 
MARQUEZ-ORTIZ, J.J.; JOHNSON, L.D.; BARNES, D.K. et al. Crown morphology relationships among alfalfa plant introductions and cultivars. Crop Science, v.36, p.766-767, 1996.

NELSON, C.J.; MOSER, L.E. Plant factors affecting forage quality. In: FAHEY JR., G.C. (Ed.). Forage quality, evaluation, and utilization. Madison: ASA, 1994. p.115-154.

NUALSRI, C.; BEUSELINCK, P.R. Rhizomatous Lotus corniculatus: IV. Inheritance of rhizomes. Crop Science, v.38, n.5, p.1175-1179, 1998.

OLIVEIRA, J.C.P.; PAIM, N.R.; FRIES, L.A. Comparação entre três procedimentos na seleção de plantas individuais em Lotus spp. Pesquisa Agropecuária Brasileira, v.25, n.7, p.955-961, 1990.

OLIVEIRA, J.C.O.; PAIM, N.R. Teste de progênie em linhas de seleção materna de duas espécies do gênero Lotus. Pesquisa Agropecuária Brasileira, v.25, n.3, p.461-467, 1990.

PAIM, N.R. Research on Lotus spp. in Rio Grande do Sul, Southern Brazil. Lotus Newsletter, v.19, p.37-43, 1988.

PEREZ, N.B. Melhoramento genético de leguminosas de clima temperado - alfafa (Medicago sativa L.) e cornichão (Lotus corniculatus L.) - para aptidão ao pastejo. Porto Alegre: Universidade Federal do Rio Grande do Sul, 2003. 175p. Tese (Programa de Pós-Graduação em Zootecnia) Universidade Federal do Rio Grande do Sul, 2003.

RUBIO, P.; ALTIER, N. Survey of fungi associated with birdsfoot trefoil seed. [Lotus Newsletter, v.26, 1995] Disponível em: <http://www.psu.missouri.edu. Acessado em 08 de janeiro de 2003.

SEANEY, R.R.; HENSON, P.R. Birdsfoot trefoil. Advances in Agronomy, v.22, p.119-157, 1970.
SOSTER, M.T.B. Caracterização morfofisiológica de genótipos de cornichão (Lotus corniculatus L.). Passo Fundo: Universidade de Passo Fundo, 2003. 106p. Dissertação (Programa de Pós-Graduação em Agronomia) - Universidade de Passo Fundo, 2003.

STEINER, J.J.; GARCIA DE LOS SANTOS, G. Adaptive ecology of Lotus corniculatus L. genotypes: I. Plant morphology and RAPD marker characterizations. Crop Science, v.41, p.552-563, 2001.

STEWART, S.; ALTIER, N. A flower blight on birdsfoot trefoil. [Lotus Newsletter, v.24, 1993]. Disponível em: http://www.psu.missouri.edu. Acessado em 8 de janeiro de 2003.

THE PLANT DISEASE DIAGNOSTIC CLINIC. Botrytis blight: factsheet. Disponível em: <http:// www.plantclinic.cornell.edu. Acessado em 12 de fevereiro de 2003.
Recebido em: 16/09/03

Aceito em: 26/04/04 